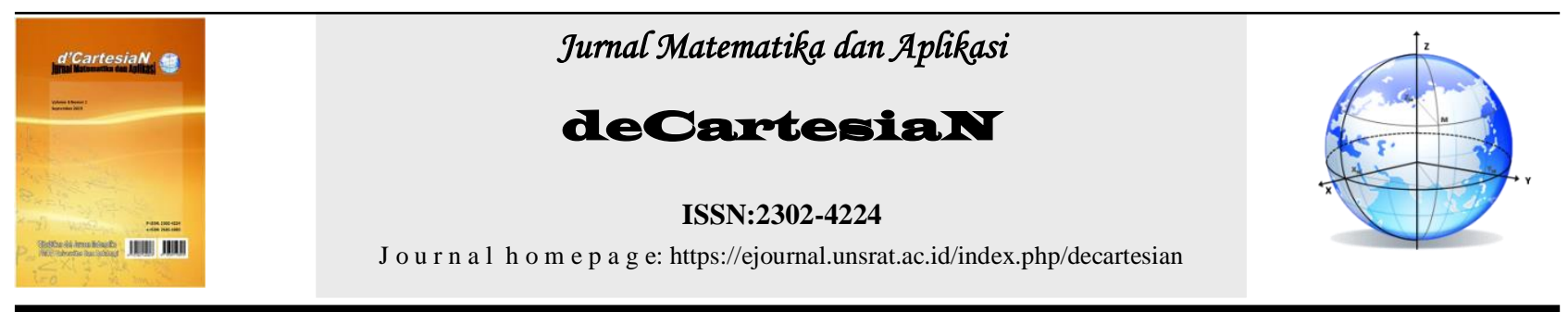

\title{
Metode Transportasi Pada Distribusi Ikan di Pelabuhan Perikanan Sulawesi Utara
}

\author{
Gustianti Batuwael' ${ }^{1}$ Marline S. Paendong ${ }^{1}$, Fernando D. Pongoh ${ }^{{ }^{*}}$ \\ ${ }^{1}$ Jurusan Matematika-Fakultas Matematika dan Ilmu Pengetahuan Alam-Universitas Sam Ratulangi Manado, Indonesia \\ ${ }^{*}$ Corressponding author : Marline_paendong@yahoo.com
}

\begin{abstract}
A B S T R A K
Pelabuhan perikanan adalah tempat pelayanan umum bagi masyarakat nelayan dan usaha perikanan, sebagai pusat pembinaan dan peningkatan kegiatan ekonomi perikanan yang digunakan untuk pangkalan operasional tempat berlabuh, mendaratkan hasil, penanganan, pengolahan, distribusi dan pemasaran hasil perikanan. Bertujuan untuk mengoptimalkan biaya distribusi ikan di pelabuhan perikanan Sulawesi Utara dari 2 sumber pelabuhan ke 6 lokasi tujuan selama tahun 2017. Metode analisis yang digunakan adalah menggunakan metode pendekatan vogel dan metode batu loncatan. Dan hasil penelitian dan perhitungan dengan program riset operasi yang diperoleh hasil bahwa pelabuhan mengeluarkan biaya distribusi ikan selama tahun 2017 sebesar Rp. 11.908.504.200.
\end{abstract}

\section{INFO ARTIKEL}

Diterima : 12 Juli 2019

Diterima setelah revisi : 24 Juli 2019

Tersedia online : 25 Juli 2019

\author{
Kata Kunci: \\ Matode Transportasi \\ VAM \\ Batu Loncatan
}

\section{ARTICLE INFO}

Received : 12 July 2019

Received after revision : 24 July 2019

Available online : 25 July 2019

\section{Keywords}

Transportation

VAM

Steping stone

\section{LATAR BELAKANG}

Pelabuhan perikanan adalah tempat pelayanan umum bagi masyarakat nelayan dan usaha perikanan, sebagai pusat pembinaan dan peningkatan kegiatan ekonomi perikanan yang dilengkapi dengan fasilitas didarat dan di perairan sekitarnya untuk digunakan sebagai pangkalan operasional tempat berlabuh, mendaratkan hasil, penanganan, pengolahan, distribusi dan pemasaran hasil perikanan [1].

Dalam mendistribusi ikan ke berbagai daerah tentunya membutuhkan biaya transportasi yang tidak sedikit jumlahnya. Untuk meminimumkan biaya distribusi perlu dilakukan perencanaan yang matang agar biaya transportasi yang dikeluarkan seefisien mungkin agar tidak menguras biaya yang besar. Besarnya biaya yang dikeluarkan perusahaan merupakan bagian masalah transportasi dalam hal pendistribusian. Salah satu metode yang dapat digunakan untuk meminimumkan biaya distribusi adalah dengan menggunakan metode transportasi.

Metode transportasi merupakan suatu metode yang digunakan untuk mengatur distribusi dari sumber yang menyediakan produk, ke tempat-tempat yang membutuhkan sehingga biaya distribusi yang dikeluarkan adalah minimum. Dalam memecahkan permasalahan pada metode transportasi terdapat 4 metode yang digunakan untuk menyelesaikan solusi awal yaitu metode arah barat laut, biaya terkecil, VAM, dan RAM. Sedangkan untuk menyelesaikan solusi optimalnya terdapat dua metode yaitu metode batu loncatan dan metode MODI.

Dalam penelitian ini digunakan metode pendekatan vogel's approximation method (VAM). Metode pendekatan vogel merupakan metode yang lebih mudah dan lebih cepat untuk mengatur alokasi dari beberapa sumber ke daerah tujuan. Solusi optimal yang digunakan dalam penelitian ini adalah metode batu loncatan untuk memastikan biaya apakah sudah minimum atau belum .

Mengetahui pentingnya pendistribusi yang tepat, maka penulis tertarik untuk melakukan penelitian dan evaluasi terhadap penyaluran distribusi ikan di sulawesi utara di dibawahi oleh Dinas Kelautan Perikanan Daerah Provinsi Sulawesi Utara untuk mencari solusi yang optimal agar biaya distribusi ikan yang dikeluarkan tepat dan merata, dimana penulis menggunakan metode transportasi untuk mengolah data dan mencari biaya distribusi ikan dengan pemilihan biaya pendistribusi yang di peroleh minimum dan optimal

Di pelabuhan Sulawesi Utara terdapat 13 kabupaten dan kota yang memproduksi ikan. Tetapi hanya 2 pelabuhan perikanan yang dikelola oleh pemerintah Sulawesi Utara. Maka dari itu peneliti mengambil 2 pelabuhan perikanan yang dikelola oleh pemerintah Provinsi Sulawesi Utara yaitu pelabuhan 
tumumpa yang terdapat di kota Manado dan pelabuhan perikanan samudra (PPS) yang terdapat di Bitung

\section{RISET OPERASI}

Riset operasi merupakan aplikasi metode, teknik teknik dan peralatan ilmiah dalam menghadapi suatu masalah-masalah yang timbul dalam sebuah operasi perusahaan dengan tujuan menemukan pemecahan yang optimal [2].

Secara umum dapat diartikan bahwa riset operasi berkaitan dengan proses pengambilan keputusan yang optimal dalam penyusunan model dari sistem-sistem ,baik deterministic maupun probabilistic, yang berasal dari kehidupan nyata [3].

\subsection{Program Linear}

Program linear adalah suatu teknik perencanaan yang dengan menggunakan model matematik dengan tujuan untuk menemukan kombinasi-kombinasi produk yang terbaik didalam menyusun suatu alokasi sumber daya yang terbatas guna untuk mencapai tujuan yang digunakan dengan cara optimal [4]

\subsection{Metode Transportasi}

Metode transportasi merupakan metode khusus dari suatu permasalahan linear programming, yang dapat digunakan untuk memecahkan masalah pengiriman komoditas dari suatu sumber ke tujuan[5]

Suatu model transportasi dikatakan seimbang apabila total supply (sumber) sama dengan total demand (tujuan). Dengan kata lain:

$$
\sum_{i=1}^{n} a_{i}=\sum_{j=1}^{n} b_{j}
$$

\section{Formulasi Metode Transportasi}

Formulasi dari metode transportasi ini adalah Fungsi Tujuan :

$\operatorname{Min} \mathrm{Z}=\sum_{i=1}^{m} \sum_{j=i}^{n}\left(x_{i j} b_{i j}\right)$

Jika jumlah produk $x_{i j}$ yang dikirimkan sama atau lebih kecil dari jumlah produk yang tersedia ditempat asal sebesar $S_{i}$ maka,kalimat matematikanya adalah $: \sum_{j=i}^{n} x_{i j} \leq S_{i}$, untuk i=1, $2, \ldots \mathrm{m}$

Jika jumlah produk yang dikirimkan ke tempat tujuan sama atau dapat juga lebih besar dari dermand $(d)$ maka, kalimat matematikanya adalah:

$\sum_{i=1}^{m} x_{i j} \leq d_{j}, \mathrm{i}=1,2, \ldots \mathrm{n}$

\subsection{Metode Pendekatan Vogel / VAM}

Metode pendekatan vogel merupakan metode yang lebih mudah dan lebih cepat untuk mengatur alokasi dari beberapa sumber kebeberapa daerah yang membutuhkan. Suatu metode yang pengalokasinya dimulai dengan menentukan nilai selisih (S) antara kotak dengan biaya terendah berikutnya untuk setiap baris dan kolom. Setelah itu pilih baris atau kolom dengan nilai $\mathrm{S}$ terbesar dan dilakukan pengalokasinya pada kotak dengan biaya terendah pada baris atau kolom yang dipilih [6].

Langkah-langkah untuk mengerjakannya adalah sebagai berikut:

1. Mengumpulkan data yang berkaitan dengan alokasi produk, yaitu biaya distribusi produk dari sumber ke tujuan. Kapasitas masing- masing gudang, dan perimintaan produk dimasing-masing tujuan.

2. Memasukkan data yang telah dikumpulkan kedalam tabel awal transportasi

3. Mencari dua biaya terendah dari masingmasing baris dan kolom

4. Menyelisikan dua biaya tersebut (biaya terendah kedua - biaya terendah pertama)

5. Memilih selisih biaya terbesar pada baris/kolom tersebut ( apabila terdapat selisih terbesar yang sama, maka dapat dipilih salah satunya).

6. Mengalokasikan produk sebanyak-banyaknya yang disesuaikan dengan kapasitas dan permintaan (pilih yang paling kecil) disel yang memiliki biaya terendah pada baris/kolom yang memiliki selisih biaya terbesar berikut.

7. Baris/kolom yang telah terisi penuh tidak dapat diikutsertakan kembali dalam proses perhitungan pencarian selisih biaya berikutnya.

8. Melakukan langak 3-6 sampai semua produk dialokasikan sesuai dengan kapasitas dan permintaan

9. Menghitung total biaya minimum distribusi dengan menggunakan persamaan 1 [7]

\subsection{Metode Batu Loncatan}

Metode yang digunakan untuk memindahkan batu dari sel satu ke sel lainnya setahap demi setahap, yang sering dan banyak digunakan untuk mengetahui atau menguji optimal tidakya tahap pertama. Dengan Langkah-langka penyusunan sebagai berikut:

1. Memilih sel kosong

2. Mencari jalur terdekat (gerakan hanya secara horizontal atau vertical)

3. Tanda (+) dan (-) muncul bergantian pada setiap sudut sel pada jalur terdekat

4. Menjumlahkan unit biaya dalam tanda (+) sebagai tanda penambahan biaya. Dan tanda (-) sebagai tanda penurunan biaya

5. Mengulangi langka 1s/d 4 untuk sel kosong tersebut

6. Melakukan perubahan jalur pada sel yang terpilih dengan cara mengalokaskan sejumlah unit terkecil dari sel bertanda kurang dan tambahkan terhadap sel bertanda tambah

7. Mengulangi langka $1 \mathrm{~s} / \mathrm{d} 6$ sampai diperoleh indeks perbaikan atau evaluasi sel kosong tidak ada yang bernilai negative[8].

\subsection{Sistem Distribusi Ikan di Pelabuhan}

Jalur distribusi adalah salah satu jalur dimana produk dan kepemilikan secara hukum mengalir dari produsen ke konsumen. Jalur distribusi di pelabuhan perikanan yaitu nelayan yang merupakan supplier utama yang menysupply semua jenis ikan kepada pihak pabrik atau perusahaan diberbagai daerah. Pabrik atau perusahaan bagi nelayan merupakan pemborong yang sudah menjadi pelanggan tetap bagi nelayan, maka pabrik atau perusahaan tidak perlu mendatangi tempat pelelangan ikan, sehingga dalam prosesnya nelayan yang akan mengantar semua jenis ikan kepada pihak pabrik atau perusahaan ikan yang ada di Sulawesi Utara. 


\section{METODOLOGI PENILITIAN}

\subsection{Waktu Dan Tempat Penelitian}

Penelitian ini dlakukan pada waktu bulan Desember 2018 sampai dengan bulan Mei 2019. Tempat pelaksanaan penelitian di Kantor Dinas Kelautan Dan Perikanan Daerah Provinsi Sulawesi Utara di jalan Kalasey Dua, Pineleng Kabupaten Minahasa, Sulawesi Utara

\subsection{Variabel Penilitian}

Variabel yang digunakan dalam penilitian ini adalah jumlah pelabuhan, jumlah tempat tujuan , permintaan, penawaran dan biaya transportasi.

\subsection{Jenis Data yang digunakan}

1. Data kuantitatif yaitu data yang diperoleh dari Kantor Dinas Kelautan Dan Perikanan Daerah Provinsi Sulawesi Utara dalam bentuk angkaangka mengenai data tahunan 2017 mencakup data produksi ikan, data tarif angkut ikan yang didistribusikan ke daerah tujuan.

2. Data kualitatif yaitu data yang diperoleh dari perusahaan dalam bentuk informasi baik lisan maupun tulisan yang sifatnya bukan angka, yaitu informasi mengenai sumber (pelabuhan), daerah tujuan pendistribusian, bagian proses distribusi, dan jenis transportasi yang digunakan.

\subsection{Prosedur Penelitian}

Pada prosedur penelitian akan dilakukan beberapa tahap yaitu antara lain:

1. Mengambil data dari Kantor Dinas Kelautan dan Perikanan di Sulawesi Utara berupa jumlah pelabuhan, jumlah tujuan, permintaan, penawaran dan biaya transportasi

2. Membuat model matematiknya

3. Menyusun data ke dalam bentuk matriks transportasi

4. Mencari solusi awal dengan menggunakan metode pendekatan vogel's approximation method (VAM) pada biaya distribusi dengan menggunakan program riset operasi

5. Mencari solusi optimal dengan menggunakan metode batu loncatan (stepping stone) untuk memastikan apakah biaya distribusi sudah optimal atau belum.

6. Mendapatkan hasil.

\section{HASIL DAN PEMBAHASAN}

\subsection{Data}

Berdasarkan data yang diperoleh dari Kantor Dinas Kelautan dan Perikanan Daerah Sulawesi Utara terdapat 13 kabupaten dan kota yang memproduksi ikan. Datadata tersebut dapat dilihat pada tabel 1.
Tabel 1. Jumlah Produksi Ikan di Sulawesi Utara Selama Tahun 2017

\begin{tabular}{|l|l|r|}
\hline No & Kabupaten/Kota & Total Produksi ikan (Ton) \\
\hline 1 & Kab. Kepulauan Talaud & $14.649,8$ \\
\hline 2 & Kab. Kepulauan Sangihe & $29.186,1$ \\
\hline 3 & Kab. Kepulauan Sitaro & $13.977,5$ \\
\hline 4 & Kab. Bolaang Mongondow & $21.690,5$ \\
\hline 5 & Kab. Bolaang Mongondow Utara & $12.823,7$ \\
\hline 6 & Kab. Minahasa Selatan & $16.000,6$ \\
\hline 7 & Kab. Minahasa & $13.089,8$ \\
\hline 8 & Kab. Minahasa Utara & $36.634,4$ \\
\hline 9 & Kab. Minahasa Tenggara & $40.758,5$ \\
\hline 10 & Kota Bitung & $56.167,4$ \\
\hline 11 & Kota Manado & $33.354,2$ \\
\hline 12 & Kab. Bolaang Mongondow Selatan & $8.242,0$ \\
\hline 13 & Kab. Bolaang Mongondow Timur & $6.223,9$ \\
\hline & & \\
\hline
\end{tabular}

Di Sulawesi Utara terdapat dua pelabuhan yang dikelolah oleh pemerintah Sulawesi Utara yaitu pelabuhan di kota Manado (Tumumpa) dan pelabuhan dikota Bitung (PPS). Tahun 2017 total produksi ikan dikota Manado sebesar 33.354,2 ton dan dikota Bitung total produksi ikan yaitu 56.167,4 ton.

Distribusi ikan di daerah tujuan dan jumlah permintaan semua jenis ikan pada tahun 2017 di dua pelabuhan dapat dilihat pada tabel 2.

Tabel 2. Distribusi Ikan di 2 Sumber Pelabuhan Sulawesi Utara Selama Tahun 2017

\begin{tabular}{|c|c|c|c|}
\hline No & Pelabuhan & Tujuan & Permintaan (Ton) \\
\hline \multirow{6}{*}{1} & \multirow{6}{*}{$\begin{array}{l}\text { Tumumpa } \\
\text { (Kota Manado) }\end{array}$} & Manado & $5.241,9$ \\
\hline & & Bitung & 10.783 .6 \\
\hline & & Minahasa utara & $2.197,4$ \\
\hline & & Minahasa Tenggara & 1.899 .6 \\
\hline & & Minahasa Selatan & $4.987,8$ \\
\hline & & Minahasa & $3.771,7$ \\
\hline \multirow{6}{*}{2} & \multirow{6}{*}{$\begin{array}{l}\text { PPS } \\
\text { (Kota Bitung) }\end{array}$} & Manado & $7.876,9$ \\
\hline & & Bitung & $15.450,4$ \\
\hline & & Minahasa utara & $3.660,5$ \\
\hline & & Minahasa tenggara & $3.321,6$ \\
\hline & & Minahasa & $3.876,9$ \\
\hline & & Minsel & 5.877 .9 \\
\hline
\end{tabular}

\subsection{Data Tarif Angkut Ikan}

Berdasarkan data yang diperoleh dari Dinas Pelabuhan Perikanan Daerah Sulawesi Utara dibuat tabel berdasarkan data tarif angkut selama tahun 2017 beserta dengan produksi ikan dan permintaan ikan dari 2 pelabuhan (PPS, Tumumpa) ke tempat tujuan selama tahun 2017. Data tersebut dapat dilihat ditabel 4. 
Tabel 3. Tarif Angkut Ikan dari Pelabuhan Ke Tujuan Tahun 2017 (Rp/Ton)

\begin{tabular}{|c|c|c|c|c|}
\hline Pelabuhan & Tujuan & $\begin{array}{c}\text { Di Angkut } \\
\text { (Ton) }\end{array}$ & $\begin{array}{c}\text { Tarif Angkut } \\
\text { (Rp/Ton) }\end{array}$ & $\begin{array}{c}\text { Jumlah Biaya } \\
\text { (Rp) }\end{array}$ \\
\hline \multirow{6}{*}{ Tumumpa } & Manado & $5.241,9$ & 160.000 & 838.704 .000 \\
\hline & Bitung & $10.783,6$ & 166.000 & 1.790 .077 .600 \\
\hline & Minut & $2.197,4$ & 168.000 & 369.163 .200 \\
\hline & Mitra & $1.899,6$ & 202.000 & 391.317 .600 \\
\hline & Minsel & $4.987,8$ & 204.000 & 967.633 .200 \\
\hline & Minahasa & $3.771,7$ & 181.000 & 682.677 .700 \\
\hline \multirow{6}{*}{ PPS } & Manado & $7.876,9$ & 166.000 & 1.307 .565 .400 \\
\hline & Bitung & $15.450,4$ & 160.000 & 2.472 .064 .000 \\
\hline & Minut & $3.660,5$ & 170.000 & 622.285 .000 \\
\hline & Mitra & $3.321,6$ & 206.000 & 670.963 .200 \\
\hline & Minahasa & $3.876,9$ & 187.000 & 724.980 .300 \\
\hline & Minsel & $5.877,9$ & 210.000 & 1.163 .824 .200 \\
\hline & Jumlah & $68.566,2$ & & 12.050 .496 .200 \\
\hline
\end{tabular}

\subsection{Analisis Dalam Bentuk Tabel Transportasi}

Data permintaan, penawaran dan biaya distribusi yang telah disajikan dalam bentuk tabel 3 Setelah itu sajikan dalam tabel transportasi seperti pada tabel 4 .

Tabel 4. Tabel awal transportasi

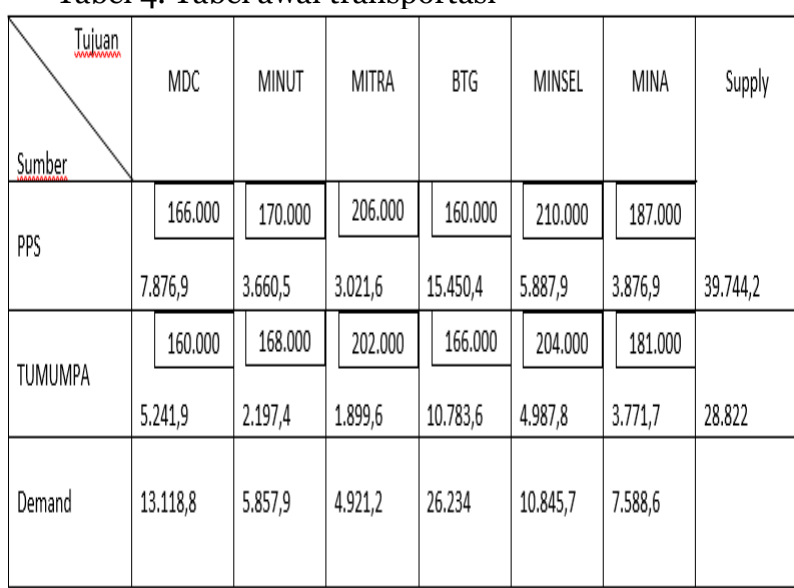

\subsubsection{Total Biaya Minimum Distribusi De Menggunakan Solusi Awal Me Vogel's Approximation (VAM)}

1. Mengumpulkan data dari pelabuhan yang berkaitan dengan alokasi ikan, yaitu biaya distribusi ikan dari sumber ke tujuan. Kapasitas masing-masing pelabuhan dan permintaan ikan dimasing-masing tujuan.

2. Memasukkan data yang telah dikumpulkan kedalam tabel awal transportasi.

3. Mencari dua biaya terendah dari masing-masing baris dan kolom
Tabel 5. Mencari dua biaya terendah dari masing-masing baris dan kolom

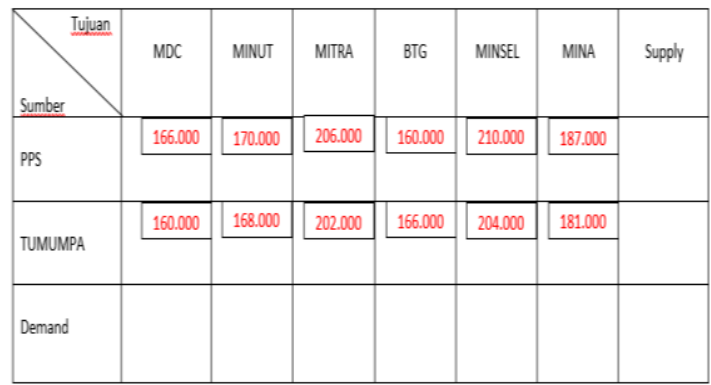

Biaya terendah pertama dan biaya terendah kedua pada baris PPS masing-masing adalah Rp.160.00o,00 dan Rp.166.ooo,oo. Sedangkan biaya terendah pertama dan kedua pada baris tumumpa masing-masing adalah Rp.160.000,oo dan Rp.166.000,oo Biaya terendah pertama dan biaya terendah kedua pada kolom MDC masing-masing adalah Rp.160.000,00 dan Rp.166.000,oo Biaya terendah pertama dan biaya terendah kedua pada kolom MINUT masing-masing adalah Rp.168.000,oo dan Rp.170.000,00 Biaya terendah pertama dan biaya terendah kedua pada kolom MITRA masing-masing adalah Rp.202.00o,oo dan Rp.206.000,00 Biaya terendah pertama dan biaya terendah kedua pada kolom BTG masing-masing adalah Rp.160.000,oo dan Rp.166.000,oo Biaya terendah pertama dan biaya terendah kedua pada kolom MINSEL masing-masing adalah Rp.204.000,00 dan Rp.210.000,oo Biaya terendah pertama dan biaya terendah kedua pada kolom MINA masing-masing adalah Rp.181.000,00 dan Rp.187.000,00

4. Selisikan dua biaya terendah (biaya terendah kedua - biaya terendah pertama).

Tabel 6. Selisikan hasil dua biaya terendah

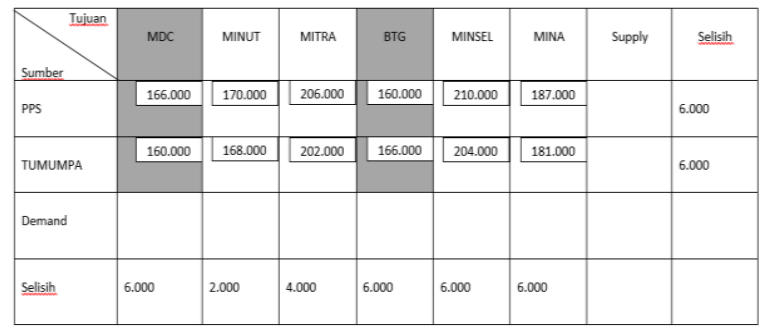

5. Memilih selisih biaya terbesar pada baris/kolom (apabilah terdapat selisih terbesar yang sama, maka dapat dipilih salah satunya)

Tabel 7. Mencari selisih terbesar

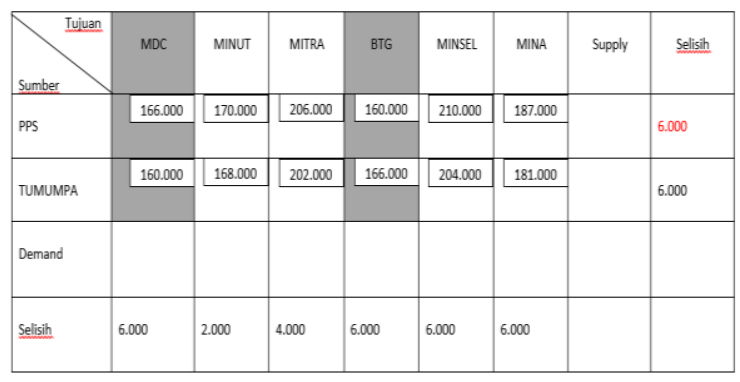

6. Mengolokasikan ikan sebanyak-banyaknya yang disesuaikan dengan kapasitas dan permintaan 
(pilih yang paling kecil) disel yang memi biaya terendah pada baris/kolom yang memi selisi biaya terbesar.

Tabel 8. Iterasi 1

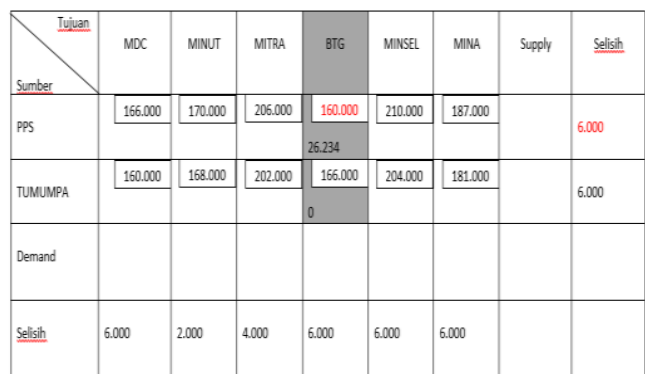

Berdasarkan iterasi 1, ditemukkan selisih terbesar berada pada baris Tumumpa yaitu Rp. 6.000,00 Pada baris PPS, dengan biaya terendah berada pada sel PPS-BTG yait Rp.160.000,00 sehingga diisi dengan 26.23 $(\min (39.744,2 ; 26.234=26.234)$. Kolom BTu tidak diikut sertakan dalam proses perhitungan pencarian selisih biaya berikutnya karena permintaannya telah terpenuhi. Oleh karena itu, sel Tumumpa-BTG diisi dengan o serta selisih pada kolom BTG untuk iterasi 2 diisi dengan tanda (-).

7. Baris/kolom yang telah diisi penuh tidak dapat diikut sertakan kembali dalam proses perhitungan pencarian selisih biaya berikutnya.

8. Melakukan langkah 3-7 sampai semua produk dialokasikan sesuai dengan kapasitas dan permintaan.

Tabel 9. Iterasi 2

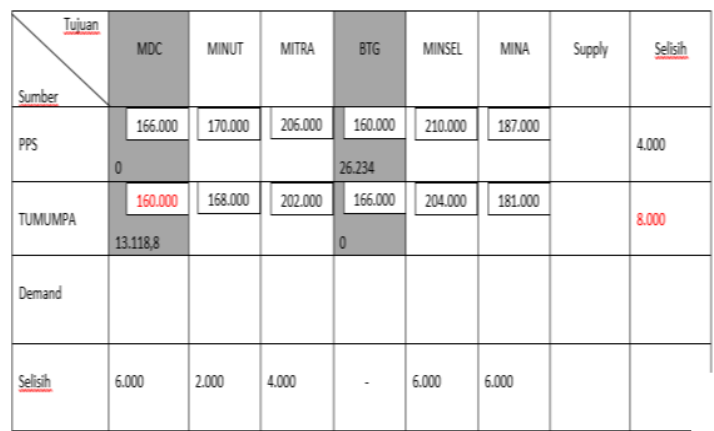

Berdasarkan iterasi 2, ditemukan selisih terbesar berada pada baris TUMUMPA yaitu Rp.8.00o,oo Pada baris TUMUMPA, dengan biaya terendah berada pada sel TUMUMPA-MDC yaitu Rp.160.000,00 sehingga diisi dengan 13.118,8 (min $(28.822 ; 13.118,8)=13.118,8)$. Kolom MDC tidak diikut sertakan dalam proses perhitungan pencarian selisih biaya berikutnya kerna permintaannya telah terpenuhi. Oleh karena itu, sel PPS-MDC diisi dengan o serta selisih pada kolom MDC untuk iterasi 3 diisi dengan tanda (-).
Tabel 10. Iterasi 3

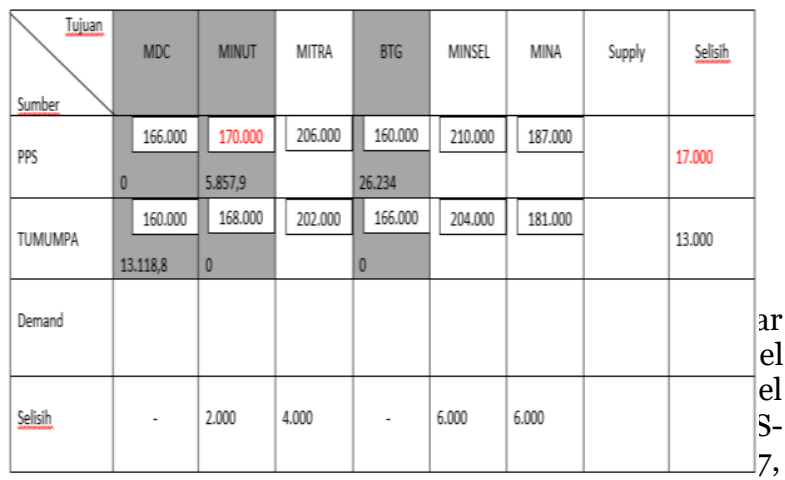

9). Kolom MINUT tidak di ikut sertakan dalam proses perhitungan pencarian selisih biaya berikutnya karena permintaannya telah terpenuhi. Oleh karena itu , TUMUMPA-MINUT disi dengan o serta selisih pada kolom MINUT untuk iterasi 4 di isi dengan tanda (-).

Tabel 11. Iterasi 4

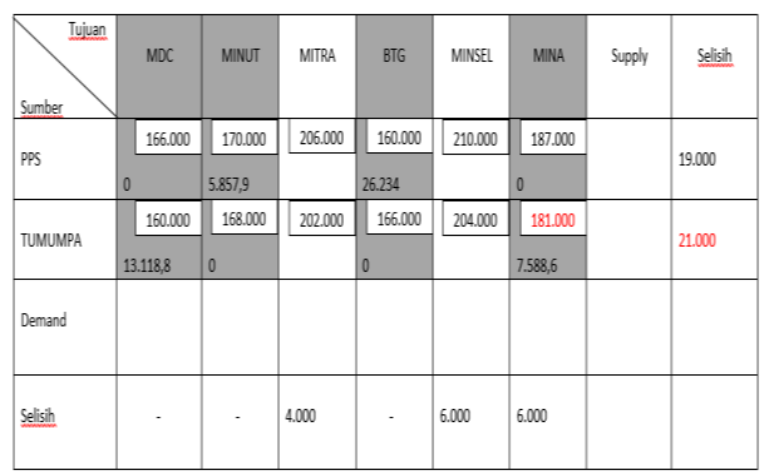

Berdasarkan iterasi 4, ditemukan selisih terbesar berada pada baris TUMUMPA yaitu Rp.21.00o,oo Pada baris TUMUMPA, sel dengan biaya terendah berada pada Tumumpa-MINA yaitu Rp.181.000,o0 sehinggan sel TUMUMPA-MINA disi dengan 7.588,6 $(\min (15 \cdot 703,2 ; 7.588,6=7 \cdot 588,6)$. Kolom MINA tidak di ikut sertakan dalam proses perhitungan pencarian selisih biaya berikutnya karena permintaannya telah terpenuhi. Oleh karena itu, sel PPS-MINA di isi dengan o serta selisih pada kolom MINA untuk iterasi 5 diisi dengan tanda (-).

Tabel 12. Iterasi 5

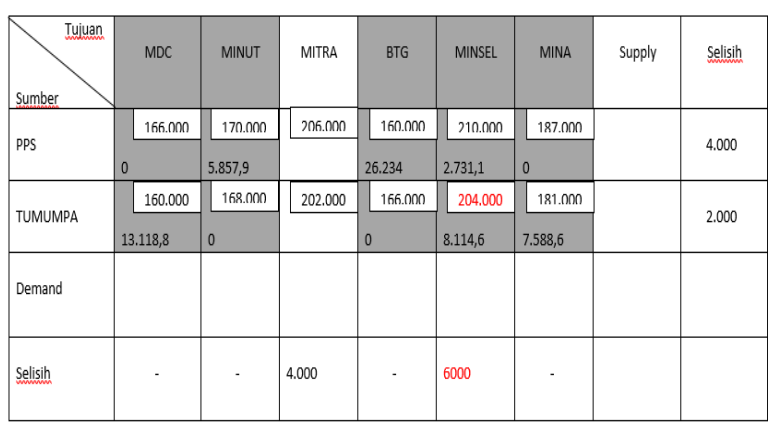

Berdasarkan iterasi 5, ditemukkan selisih terbesar pada kolom MINSEL yaitu Rp.6.00o,oo Pada kolom MINSEL, sel dengan biaya terendah adalah Rp.204.000,oo sehingga sel TUMUMPAMINSEL diis i dengan 8.114,6 ( $\min 8.114,6 ; 8.114,6=8.114,6)$. Kolom PPS-MINSEL diisi 2.731,1 karena pada baris TUMUMPA telah tepenuhi kapasitasnya. Oleh karena itu selisih pada 
baris PPS,TUMUMPA dan kolom MINSEL iterasi 6 diisi dengan tanda (-).

Tabel 13. Iterasi 6

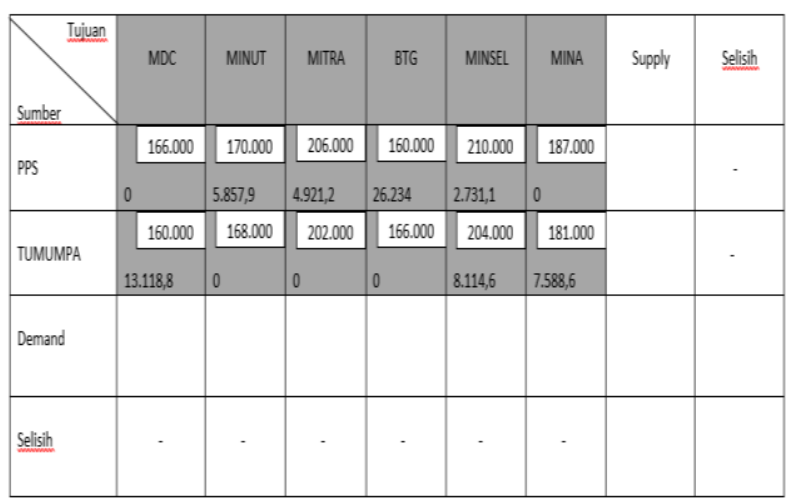

Berdasarkan iterasi 6, tidak perlu mencari selisih biaya lagi karena hanya ada satu sel kosong yang tersisa yang belum terpenuhi kapasitasnya yaitu pada sel PPS-MITRA dapat langsung di isi dengan 4.619(min 4.619;4.619=4.619). Kapasitas PPS menjadi 4.921,2 $(39.744,2-34.823=4.921,2)$ karena sebelumnya telah disi baris PPS dengan jumlah 34.823 ton serta permintaan MITRA menjadi 4.921,2 ton.

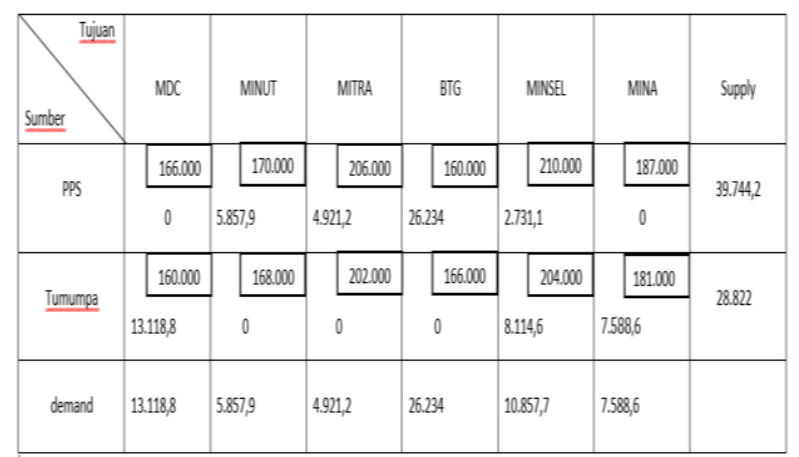

Berdasarkan tabel 14, terlihat bahwa seluruh kebutuhan baris dan kolom sudah terpenuhi yang berarti solusi awal telah diperoleh.

9. Menghitung total biaya minimum distribusi menggunakan persamaan 2.2

$$
\begin{aligned}
= & 160.000 X_{11}+170.000 X_{12}+206.000 X_{13}+160.000 X_{14}+ \\
& 210.00015+187.000 X_{16}+160.000 X_{21}+168.000 X_{22}+ \\
& 202.000 X_{23}+166.000 X_{24}+204.000 X_{25}+181.000 X_{26} \\
= & (160.000 \times 0)+(170.000 \times 5.857,9)+(206.000 \times 4.921,2)+ \\
& (160.000 \times 26.234)+(210.000 \times 2.731,1)+(187.000 \times 0)+ \\
& (160.000 \times 13.118,8)+(168.000 \times 0)+(202.000 \times 0)+ \\
& (166.000 \times 0)+(204.000 \times 8.114,6)+(181.000 \times 7.588,6)
\end{aligned}
$$$$
=(0)+(995.843 .000)+(1.013 .767 .200)+(4.197 .440 .000)+
$$$$
(436.976 .000)+(0)+(2.099 .008 .000)+(0)+(0)+(0)+
$$$$
(1.655 .378 .400)+(1.373 .536 .600)
$$

$=11.908 .504 .200$
4.3.2 Total biaya untuk lebih memastikan apakah biaya sudah minimum dan optimal menggunakan metode Stepping Stone ( Batu Loncatan)

1. Menghitung solusi akhir metode transportasi untuk mengetahui keoptimal data awal dengan menggunakan metode batu loncatan.

a) Melakukan proses tes optimalisasi dengan menggunakan solusi awal yang lebih dikerjakan diatas yaitu metode VAM, selanjutnya dilakukan pengujian solusi optimal menggunakan metode batu loncatan untuk memastikan apakah biaya transportasi tersebut telah minimum. Untuk berlanjut ke pengujian optimal harus memenuhi syarat yaitu $\mathrm{m}+\mathrm{n}-1$, dimana $(\mathrm{m}=$ baris/gudang dan $\mathrm{n}=$ kolom/cabang) pada kasus ini telah memenuhi syarat $(2+6-2=6)$ karena jumlah sel yang terisi adalah 6. Dengan demikian dapat dilakukan pengujian menggunakan solusi optimal.

2. Pengujian optimal untuk metode VAM

a) Memilih sel yang kosong pada setiap baris dan kolom , selanjutnya melakukan loncatan pada sel yang terisi dan dapat dilakukan secara horizontal atau vertical dan diberi tanda + pada sel kosong dan

\begin{tabular}{|c|c|c|c|c|c|c|c|}
\hline (lugad & MDC & MNUT & MTRA & BTG & Minsel & MNA & Supply \\
\hline \multirow{2}{*}{ PPS } & 166.000 & 170.000 & 206.000 & 160.000 & 210.000 & 187.000 & \multirow{2}{*}{$39.744,2$} \\
\hline & $x_{12}{ }^{\top}$ & $5.857,9$ & $4.921,2$ & 26.234 & 2731,1 & $x_{16}$ & \\
\hline \multirow{2}{*}{ Tumumpa } & 160.000 & 168.000 & 2020000 & 166.000 & 204.000 & 181.000 & \multirow{2}{*}{28.822} \\
\hline & $13.118,8$ & $x_{22}$ & $x_{23}$ & $x_{24}$ & $8.114,6$ & 7588,6 & \\
\hline demand & 13.118,8 & $5.857,9$ & $4.921,2$ & 26.234 & $10.857,7$ & $7.588,6$ & \\
\hline
\end{tabular}
selanjutnya tanda - secara bergantian, batu loncatan bersifat genap.

Tabel 15. Alokasi solusi optimal metode batu loncatan.

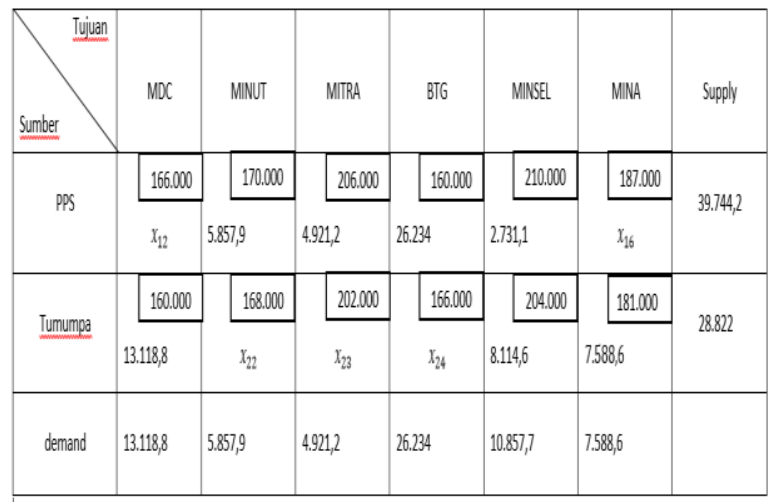

Tabel 16. Stepping stone tahap 1 
Tabel 17. Stepping stone tahap 2

\begin{tabular}{|c|c|c|c|c|c|c|c|}
\hline Tuya & $M O C$ & MNUT & MTRA & BTG & MNSEl. & MNA & Supply \\
\hline \multirow{2}{*}{$P P S$} & 166.000 & 170.000 & 2060000 & 1600000 & 210.000 & 187,000 & \multirow{2}{*}{$39.744,2$} \\
\hline & $x_{12}$ & $5.857,9$ & $4.921,2$ & 26.234 & 2731,1 & $7 x_{16}$ & \\
\hline \multirow{2}{*}{ Tumumpa } & 1600000 & 168.000 & 202000 & 1660000 & 204,000 & 181.000 & \multirow{2}{*}{28.822} \\
\hline & $13: 118,8$ & $x_{22}$ & $x_{23}$ & $x_{24}$ & $8.114,66^{\prime}$ & 7588,6 & \\
\hline demand & $13.1188,8$ & $5.857,9$ & 4.921,2 & 26.234 & $10.857,7$ & 7588,6 & \\
\hline
\end{tabular}

Tabel 18. Stepping stone tahap 3

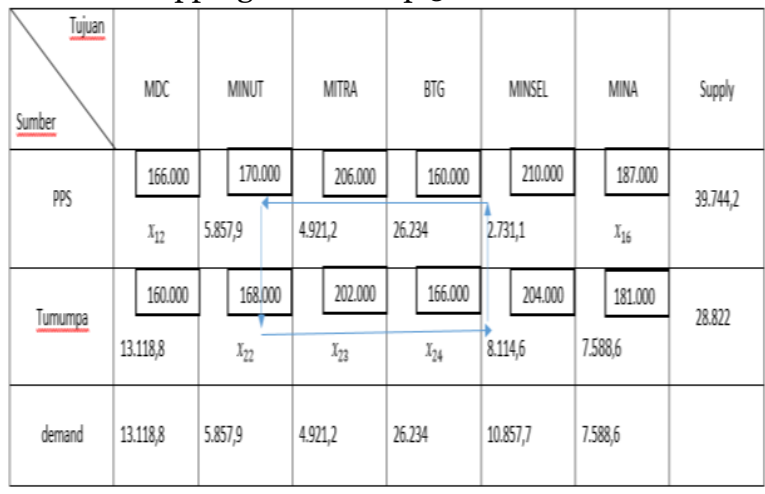

Tabel 19. Stepping stone tahap 4

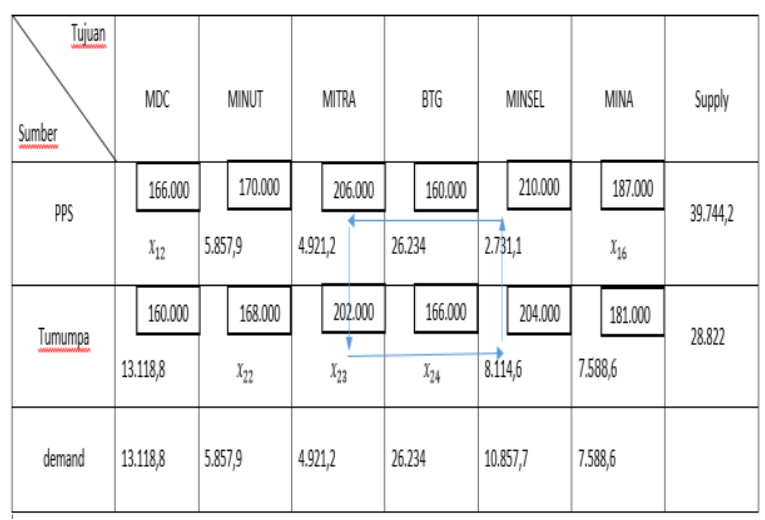

Tabel 20. Stepping stone tahap 5

\begin{tabular}{|c|c|c|c|c|c|c|c|}
\hline Sumber & MOC & MNUT & MTRA & BTG & Mnsel. & MNA & Supply \\
\hline \multirow{2}{*}{ PPS } & 166000 & 170.000 & 206,000 & 160.000 & 2100000 & 187.000 & \multirow{2}{*}{$39.744,2$} \\
\hline & $x_{12}$ & $5.857,9$ & $4.921,2$ & 26.234 & 2731,1 & $x_{16}$ & \\
\hline \multirow{2}{*}{ Tumumpa } & 160.000 & 1680000 & 2020000 & 166.000 & 204,000 & 181.000 & \multirow{2}{*}{28.822} \\
\hline & $13.118,8$ & $x_{22}$ & $x_{23}$ & $x_{24}$ & $8.114,6$ & 7588,6 & \\
\hline demand & 13:1188,8 & $5.857,9$ & $4.921,2$ & 26.234 & 10.857, & 7588,6 & \\
\hline
\end{tabular}

Pergerakan batu loncatan dari sel yang kosong menuju sel yang terisi dan akhirnya kembali ke sel semula.Sel-sel yang kosong adalah:

PPS-MDC $=166.000-210.000+204.000-160.000=0$ PPS-MINA $=187.000-181.000+204.000-210.000$ $=0$

TUMUMPA-MINUT $=168.000-204.000+210.000-$

$$
170.000=4.000
$$

TUMUMPA - MITRA $=202.000-204.000+210.000$ $-206.000=2.000$

TUMUMPA - BTG $=166.000-204.000+210.000-$ $160.000=12.000$

Kesimpulan : karena hasil dari perhitungan tidak ditemukkan negatif (penghematan biaya), maka proses eksekusi telah selesai. Alokasi ikan dari sumber ketempat tujuan menurut pendekatan Vogel (VAM) yang diuji oleh metode batu loncatan sebagai berikut.

Tabel 21. Hasil dari Metode Batu Loncatan

\begin{tabular}{|c|c|c|c|c|}
\hline Dari & Tujuan & Di angkut & $\begin{array}{c}\text { Biaya ton } \\
(\mathrm{Rp})\end{array}$ & $\begin{array}{c}\text { Jumlah biaya } \\
(\mathrm{Rp})\end{array}$ \\
\hline PPS & MINUT & $5.857,9$ & 170.000 & 995.843 .000 \\
\hline PPS & MITRA & $4.921,2$ & 206.000 & 1.013 .767 .200 \\
\hline PPS & $\mathrm{BTG}$ & 26.234 & 160.000 & 4.197 .440 .000 \\
\hline PPS & MINSEL & $2.731,1$ & 210.000 & 573.531 .000 \\
\hline TUMUMA & $\mathrm{MDC}$ & $13.118,8$ & 160.000 & 2.099 .008 .000 \\
\hline TUMUMA & MINSEL & $8.114,6$ & 204.000 & 1.655 .378 .400 \\
\hline TUMUMPA & MINA & $7.588,6$ & 181.000 & 1.373 .536 .600 \\
\hline & Total biaya & & & 11.908 .504 .200 \\
\hline
\end{tabular}

Dari hasil perhitungan penilitian di atas, peneliti mencari solusi untuk mendapatkan biaya transportasi yang minimum agar dapat mengehemat biaya-biaya total pengiriman ikan dari sumber ke tempat tujuan. Metode yang digunakan adalah metode VAM dan untuk memastikan apakah biaya telah optimal atau belum digunakan metode batu loncatan. Dan hasil yang didapat dari metode batu loncatan adalah Rp. 11.908.508.200,00 Pada tabel 22 dapat dilihat perbandingan dari jalur distribusi asli, metode VAM, dan metode batu loncatan (Stepping stone).

Tabel 22. Perbandingan hasil analisis metode transportasi

\begin{tabular}{|c|c|}
\hline Jalur Distribusi & Biaya \\
\hline Pelabuhan & 12.050 .496 .200 \\
\hline VAM & 11.908 .504 .200 \\
\hline Batu loncatan & 11.908 .504 .200 \\
\hline
\end{tabular}

Pelabuhan mengeluarkan biaya trasnportasi sebesar Rp. 12.050.496.200,00 sedangkan menggunakan metode 
VAM biaya yang akan dikeluarkan sebesar Rp. 11.908.504.200. Menggunakan metode VAM biaya yang dikeluarkan ternyata lebih menguntungkan dibandingkan biaya asli dari pelabuhan. Dan untuk memastikan apakah biaya telah optimal atau belum maka diuji menggunakan metode batu loncatan dan hasilnya sebesar Rp. 11.908.504.200, dengan menggunakan metode batu loncatan hasilnya sudah optimal.

\section{KESIMPULAN DAN SARAN}

5.1 Kesimpulan

Berdasarkan hasil dan pembahasan yang telah dilakukan maka dapat disimpulkan sebagai berikut

1. jalur metode transportasi lebih efisien di bandingkan jalur distribusi yang ada sebelumnya dari pelabuhan perikanan

2. jalur distribusi menggunakan metode vogel dan untuk mengoptimalkan biaya distribusi menggunakan metode batu loncatan selama tahun 2017 yaitu sebesar Rp. 11.908.504.200,00 , lebih efisien dibandingkan jalur dstribusi ikan yang digunakan dari pelabuhan Sulawesi Utara selama ini pada tahun 2017 sebesar Rp. 12.050.496.200,00.

\subsection{Saran}

Berdasarkan kesimpulan tersebut, penulis berharap kepada perusahan tersebut agar metode pendekatan Vogel dapat dipertimbangkan oleh perusahaan untuk menghitung biaya transportasi, karena metode ini lebih dapat menekan biaya transportasi yang akan dikeluarkan.

\section{REFERENSI}

[1] Departemen Kelautan dan Perikanan. 2006. Surat Menteri peraturan Menteri Kelautan dan Perikanan Nomor PER.16/MEN/2006 tentang pelabuhan perikanan. Jakarta.

[2] Churchman, et al. (1959). "Introduction to Operatio Research'. Publisher John Wiley and Sons. New York.

[3] Aminudin.2005. Prinsip-prinsip Riset Operasi. Erlangga. Jakarta.

[4] Assauri. 1999. Manajemen Produksi dan Operasi, Lembaga Penerbit Fakultas Ekonomi Universitas Indonesia, Jakarta.

[5] A Taha, Hamdy (2003). Riset Operasi Edisi Kelima Jilid I. Binarupa Aksara, Jakarta.

[6] Bernard, 2007. Analisis Perbandingan Metod Pendektan Vogel Metode Pendekatan Russell,dan Metode Mulitplier unntuk Transshipment Roti pada Lauw Bakery,[Skripsi], FMIPA UBN, Jakarta.

[7] Zainuddin 2011. Analisis Penerapan Model Transportasi dan Distribusi (Dengan VAM dan MODI) Pada PT. Coca-Cola Bottling Indonesia [Skripsi]. Makassar : Universitas Hassanudin Makassar.
[8] Aminudin.2005. Prinsip-prinsip Riset Operasi. Erlangga. Jakarta.

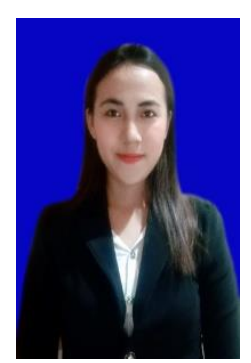

Gustianti Batuwael

(Gustiantib@gmail.com)

Lahir di Ambon pada tanggal 7 Agustus 1996. Menempuh pendidikan tinggi Jurusan Matematika, FMIPA, Universitas Sam Ratulangi Manado. Tahun 2019 adalah tahun terakhir ia menempuh studi. Makalah ini merupakan hasil penelitian skripsinya yang dipublikasikan.

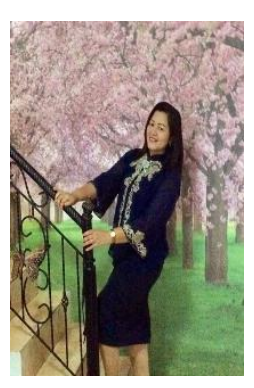

\section{Marline S. Paendong}

(Marline_Paendong@yahoo.com)

Pada tahun 1999, memperoleh gelar sarjana di Program Studi Matematika, Universitas Gadjah Mada. Gelar magister Sains diperoleh di Institut Pertanian Bogor pada tahun 2006. Ia bekerja di UNSRAT di Program Studi Matematika sebagai pengajar akademik tetap dan bekerja di Kantor Rektorat UNSRAT sebagai Lektor.

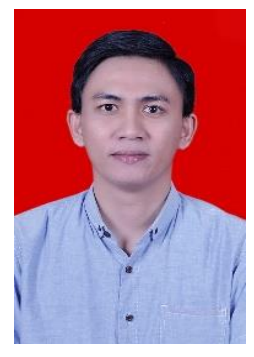

\section{Fernado D. Pongo}

(fernando.pongoh@gmail.com)

Lahir pada tanggal 23 september 1987 di Manado. Pada tahun 2010 memperoleh sarjana Sains (S.Si) di Matematika UNSRAT. Gelar Magister Sains diperoleh di Statistika Terapan IPB tahun 2015. Saat ini mengajar di jurusan Matematika UNSRAT, matakuliah Statistika, regresi, dan peubah ganda 